\title{
Agricultural Commodities and their Financialization
}

\author{
Bernard, Lucas \\ Greiner, Alfred \\ Semmler, Willi
}

- Received: 12 february 2012

- ACCEPTED: 29 JUNE 2012

\begin{abstract}
Agricultural commodities, here considered as renewable products, are critical to many developing countries. Not only are their prices rising, along with price volatility on both spot and futures markets, but also an increasing financialization of these products is making itself felt. All this may become a threat to many segments of the populations of low income countries. In this paper, we build a model to help understand how the economic and financial effects interact to produce, for example, food shortages. We explore the consequences and potentials for control.
\end{abstract}

\section{Keywords:}

Renewable products, Agricultural commodities, Food shortages, Financialization.

JEL classification:

G15, Q14, C61

Bernard, L. The City University of New York, College of Technology, Department of Business, 300 Jay Street, Brooklyn, NY I I 20 I. E-mail:LBernard@CityTech.CUNY.edu

Greiner,A. Department of Business Administration and Economics, Bielefeld University, P.O. Box 100131, 3350I. Bielefeld, Germany. E-mail: agreiner@wiwi.uni-bielefeld.de

Semmler,W. Department of Economics, The New School for Social Research, 6 East I6th Street, New York, NY 10003, USA.

E-mail:semmlerw@newschool.edu 


\title{
Los productos básicos agrícolas y su financialización
}

\author{
Bernard, Lucas \\ Greiner, Alfred \\ Semmler, Willi
}

\begin{abstract}
Resumen
Los productos básicos agrícolas, en este artículo considerados como productos renovables, son esenciales para muchos países en desarrollo. Ya se está apreciando un aumento de sus precios, y de la volatilidad de los mismos tanto en los mercados de contado como en los de futuro, así como también una creciente financialización de estos productos, lo cual puede convertirse en una amenaza para muchos segmentos de la población de los países de renta baja. En este trabajo, se construye un modelo para ayudar a entender cómo interactúan los efectos económicos y financieros para dar lugar, por ejemplo, a una situación de escasez de alimentos. También se analizan sus consecuencias y las posibilidades de control.
\end{abstract}

\section{Palabras clave:}

Productos renovables, productos básicos agrícolas, escasez de alimentos, financialización. 


\section{Introduction}

For several years now, international newspapers have been reporting on a new wave of food shortages and the rising price of commodities, in particular for basic agricultural products. The heat waves during summer 2010 in Russia, Europe and the US, together with the flooding in Asia (Pakistan) sent food prices in both spot and futures markets soaring, setting off fears of a tight supply not only for 2010, but the subsequent years as well. In 2011, the news on food shortages continued. The effects of global warming and the aforementioned heat waves in some regions of the world have created droughts, produced deserts, and made formerly cultivated land unusable for agricultural purposes. Moreover, the usable agricultural land has been reduced in some parts of the world, for example in Brazil and in the US, to produce bio-fuel, or to use land for developing housing or tourist centers in coastal areas. Since the prices of non- renewable resources, such as oil, gas, minerals and metals have been soaring too, the energy-intensive agricultural production in advanced countries has also experienced a cost push in the production of agricultural products.

There is a general pressure for price increases despite a large number of countries still suffering from the financial and economic meltdown of the years 2007-2009; the situation becomes more complicated when one considers that, since agricultural products, e.g., corn, are a major feed source for livestock, these too can only be produced at higher cost. Yet, not only does there seem to be an upward price trend for the basic agricultural products, which we will call renewable resources (in contrast to the non-renewable resources), but there also seems to be rising price volatility as well. All those problems may become amplified by cascade-like rising temperatures, as climate researchers predict. Furthermore there is a trend toward the financialization of such scarce products which may exacerbate these trends.

The remainder of the paper is organized as follows. In Section 2 we will sketch simple model variants that may explain price trends for basic renewable produces. Section 3 discusses additional factors driving prices. In section 4 we discuss trends and volatility in the data for agricultural products. Section 5 discusses the financialization of agricultural commodities more specifically and elaborates on potentials for control. Section 6 concludes the paper.

\section{A Dynamic Model of Renewable Commodities}

We first want to introduce two basic model variants that might help us to understand the price trends and volatility of renewable products. Instead of employing only agricultural production functions we use a dynamical systems 
approach, e.g., a Lotka-Volterra system. Lotka-Volterra systems have successfully been applied to understand both renewable resources and business cycles. They portray the interaction of different types of renewables through three types of mechanisms: a predator-prey, competitive, and cooperative interaction. Those can give rise to quite complex dynamics. Yet, we will also introduce agents' actions that intervene into the basic interactions of the resources by increasing their productivity as well as harvesting them.

Let us assume a simple model. It is basically a predator-prey model enlarged by cooperative and inner-specific competition effects. The model is written as follows.

The variable $x(t)$ stands for the stock of agricultural products. ${ }^{1}$ The change in the stock of agricultural products positively depends on land, $z$, and positively on agricultural products invested, $x-c_{x}$, with $c_{x}$ agricultural products that are consumed. Further, the growth of agricultural products is negatively affected by parasites, $y$. Thus, the differential equation describing the change of $x$ can be written as,

$$
\dot{x}=f\left(c_{x}, z\right)-a y x=\left(x-c_{x}\right) h z^{\gamma}-a y x, x(0)=x_{0},
$$

with $a, h>0$ and $\gamma \in(0,1)$ constant parameters.

Parasites grow stronger if more food is available and they die at a constant rate $b>0$. Further, we allow for inner-specific competition meaning that the change in the number of parasites is smaller, the higher the level of parasites is. This gives rise to the following differential equation describing the evolution of parasites over time:

$$
\dot{y}=-b y+e y x-d y^{2}, y(0)=y_{0},
$$

where $e, d>0$ are again constant parameters.

Finally, land available for producing agricultural products, $z$, evolves according to the following differential equation,

$$
\dot{z}=n z(K-z)-c_{z}, z(0)=z_{0},
$$

with $n, K>0$ constant parameters and $c_{z}$ that amount of land that becomes lost for agricultural production since it is consumed, i.e., it is used for building cities or tourist attractions in coastal areas. The differential equation (3) implies that the evolution of land displays an S-shaped form, where new land is obtained by defor-

I The argument $t$ denotes time and will be deleted in the following as long as no unambiguity arises. 
estation and by irrigation of deserts for example. The motivation for using an S-shaped function is that first land is cultivated that can be used for producing food. As more and more land is used it becomes more difficult to obtain additional land such that the change of land for producing agricultural products becomes a concave function.

The goal of a planner, then, is to maximize utility arising from consumption of agricultural products and of land over an infinite time horizon subject to the evolution of agricultural products, subject to the change of parasites and subject to the change of land available for agricultural products. Formally, the optimization problem is written as,

$$
\max _{c_{x}, c_{z}} \int_{0}^{\infty} e^{-\rho t} \frac{\left[\left(c_{x}\right)^{\alpha}\left(c_{z}\right)^{\beta}\right]^{1-\sigma}-1}{1-\sigma} d t
$$

subject to (1), (2), (3), where $\rho$ gives the subjective rate of time preference.

To find necessary optimality conditions we resort to optimal decision theory and formulate the current-value Hamiltonian $H(\cdot)$ which is written as:

$$
H=\frac{\left[\left(c_{x}\right)^{\alpha}\left(c_{z}\right)^{\beta}\right]^{1-\sigma}-1}{1-\sigma}+\lambda_{1}\left(\left(x-c_{x}\right) h z^{\gamma}-a y x\right)+\lambda_{2}\left(-b y+e y x-d y^{2}\right)+\lambda_{3}\left(n z(K-z)-c_{z}\right),
$$

with $\lambda_{i}, i=1,2,3$, the shadow prices of agricultural products, of parasites and of land, respectively.

In order to maximize the Hamiltonian with respect to the decision variables $c_{x}$ and $c_{z}$ we compute the first-order conditions and set them equal to zero giving,

$$
\begin{aligned}
& \frac{\partial H}{\partial c_{x}}=\frac{\alpha\left(c_{x}^{\alpha} c_{z}^{\beta}\right)^{1-\sigma}}{c_{x}}-h \lambda_{1} z^{\gamma}=0 \\
& \frac{\partial H}{\partial c_{z}}=\frac{\beta\left(c_{x}^{\alpha} c_{z}^{\beta}\right)^{1-\sigma}}{c_{z}}-\lambda_{3}=0
\end{aligned}
$$

Since the Hamiltonian is jointly concave in the controls, the two equations (5) and (6) guarantee that the Hamiltonian is maximized by those values of $c_{x}$ and $c_{z}$ that satisfy those equations. 
The other necessary optimality conditions are obtained as,

$$
\begin{aligned}
& \dot{\lambda}_{1}=\lambda_{1} \rho-e \lambda_{2} y-\lambda_{1}\left(h z^{\gamma}-a y\right) \\
& \dot{\lambda}_{2}=\lambda_{2} \rho+a \lambda_{1} x-\lambda_{2}(-b+e x-2 d y) \\
& \dot{\lambda}_{3}=\lambda_{3} \rho-\lambda_{3}(n(K-z)-n z)-\lambda_{1} \gamma h z^{\gamma-1}\left(x-c_{x}\right)
\end{aligned}
$$

Further, we require that the limiting transversality conditions

$$
\lim _{t \rightarrow \infty} e^{-\rho t} \lambda_{1} x=0, \lim _{t \rightarrow \infty} e^{-\rho t} \lambda_{2} y=0, \lim _{t \rightarrow \infty} e^{-\rho t} \lambda_{3} z=0
$$

hold. $^{2}$

Solving equations (5) and (6) leads to,

$$
\begin{aligned}
& c_{x}=\left(\frac{\lambda_{3}}{\beta}\right)^{\frac{1}{\alpha(1-\sigma)}}\left(\left(\frac{\lambda_{3}}{\beta}\right)^{\frac{1-\alpha(1-\sigma)}{\alpha(1-\sigma)+\beta(1-\sigma)-1}}\left(\frac{h \lambda_{1} z^{\gamma}}{\alpha}\right)^{\frac{\alpha(1-\sigma)}{\alpha(1-\sigma)+\beta(1-\sigma)-1}}\right)^{\frac{1-\beta(1-\sigma)}{\alpha(1-\sigma)}} \\
& c_{z}=\left(\frac{\lambda_{3}}{\beta}\right)^{((1-\alpha(1-\sigma)) /(-1+\alpha(1-\sigma)+\beta(1-\sigma)))}\left(\frac{h \lambda_{1} z^{\gamma}}{\alpha}\right)^{((\alpha(1-\sigma)) /(-1+\alpha(1-\sigma)+\beta(1-\sigma)))}
\end{aligned}
$$

Inserting (10) and (11) into the equations (1)-(3) and (7)-(9) gives a 6-dimensional autonomous system of ordinary differential equations which completely describes our economy over time. This system of differential equations is given by

$$
\begin{aligned}
\dot{x}= & -h\left(\frac{\lambda_{3}}{\beta}\right)^{\frac{1}{\alpha(1-\sigma)}}\left(\left(\frac{\lambda_{3}}{\beta}\right)^{\frac{1-\alpha(1-\sigma)}{\alpha(1-\sigma)+\beta(1-\sigma)-1}}\left(\frac{h \lambda_{1} z^{\gamma}}{\alpha}\right)^{\frac{\alpha(1-\sigma)}{\alpha(1-\sigma)+\beta(1-\sigma)-1}}\right)^{\frac{1-\beta(1-\sigma)}{\alpha(1-\sigma)}} z^{\gamma+} \\
& h x z^{\gamma}-a x y, x(0)=x_{0} \\
\dot{y}= & -d y^{2}-b y+e x y, y(0)=y_{0} \\
\dot{z}= & n(K-z) z-\left(\frac{\lambda_{3}}{\beta}\right)^{\frac{1-\alpha(1-\sigma)}{\alpha(1-\sigma)+\beta(1-\sigma)-1}}\left(\frac{h \lambda_{1} z^{\gamma}}{\alpha}\right)^{\frac{\alpha(1-\sigma)}{\alpha(1-\sigma)+\beta(1-\sigma)-1}}, z(0)=z_{0} \\
\dot{\lambda}_{1}= & \lambda_{1} \rho-e \lambda_{2} y-\lambda_{1}\left(h z^{\gamma}-a y\right), \lambda_{1}(0) \\
\dot{\lambda}_{2}= & \lambda_{2} \rho+a \lambda_{1} x-\lambda_{2}(-b+e x-2 d y), \lambda_{2}(0) \\
\dot{\lambda}_{3}= & \lambda_{1} \gamma h z^{\gamma-1}\left(\frac{\lambda_{3}}{\beta}\right)^{\frac{1}{\alpha(1-\sigma)}}\left(\left(\frac{\lambda_{3}}{\beta}\right)^{\frac{1-\alpha(1-\sigma)}{\alpha(1-\sigma)+\beta(1-\sigma)-1}}\left(\frac{h \lambda_{1} z^{\gamma}}{\alpha}\right)^{\frac{\alpha(1-\sigma)+\beta(1-\sigma)-1}{\alpha(1-\sigma)}}\right)^{\frac{1-\beta(1-\sigma)}{\alpha(1-\sigma)}}+ \\
& \lambda_{3} \rho-\lambda_{3}(n(K-z)-n z)-\lambda_{1} \gamma h z^{\gamma-1} x, \lambda_{3}(0)
\end{aligned}
$$

A rest point of (12)-(17) yields a steady-state for our model economy.

\footnotetext{
${ }^{2}$ Since the Hamiltonian is not jointly concave in the control and state variables, we cannot apply the usual theorems guaranteeing that the necessary conditions are also sufficient.
} 
Since our model described by the system (12)-(17) is rather complex, we resort to numerical examples in order to get additional insight into its structure. To do so we assume the following parameter values: $n=0.3, K=1, \sigma=2, \alpha=0.5, \beta=0.5, a=0.75$, $b=1.1, e=0.2, d=0.1$. Further, we set $\gamma=0.5, h=0.5$ and $\rho=0.03$. With these parameter values we get the following steady-state, ${ }^{3}$

$\left\{x^{*}, y^{*}, z^{*}, \lambda_{1}^{*}, \lambda_{2}^{*}, \lambda_{3}^{*}, c_{x}^{*}, c_{z}^{*}\right\}=\{5.506,0.011,0.454,0.438,-58.095,10.645,5.368,0.074\}$

The eigenvalues of the Jacobian matrix evaluated at this steady-state are given by:

$$
\mu_{1}=0.240, \mu_{2,3}=0.209 \pm 0.034 i, \mu_{4}=-0.210, \mu_{5,6}=-0.179 \pm 0.034 i
$$

Thus, the dynamics are characterized by a saddle point with transitory oscillations until the steady-sate is reached in the long-run. Saddle point stability means that there exist unique values for $\lambda_{i}(0), i=1,2,3$, lying on the stable manifold so that the economy converges to the steady-state.

Reducing the rate of time preference $\rho$, the system becomes more stable in the sense that the transitory oscillations vanish. Then, all eigenvalues are real with three being negative and three being positive. In our example, all eigenvalues are real numbers for $\rho \leq 0.0185$. If we increase the rate of time preference the system becomes unstable and the number of parasites becomes negative, which is the case for $\rho \approx 0.205$ in our example. Further, it should be noted that the system does not undergo a Hopf bifurcation as the rate of time preference is increased. ${ }^{4}$

Next, let us assume that the productivity of the food production is increased. Formally, this means that the parameter $h$ rises. Setting $h=1$ and the rate of time preference to $\rho=0.03$ as above we get the following steady-state:

$\left\{x^{*}, y^{*}, z^{*}, \lambda_{1}^{*}, \lambda_{2}^{*}, \lambda_{3}^{*}, c_{x}^{*}, c_{z}^{*}\right\}=\{5.512,0.025,0.454,0.219,-27.927,10.649,5.362,0.074\}$

and the eigenvalues of the Jacobian are,

$$
\mu_{1}=0.621, \mu_{2}=-0.591, \mu_{3}=0.201, \mu_{4}=0.174, \mu_{5}=-0.171, \mu_{6}=-0.144
$$

This shows that the dynamics are a saddle point, but there are no more transitory oscillations, in contrast to the case with a lower productivity of the input factors in the production of food. Thus, a higher productivity tends to stabilize the economy.

\footnotetext{
${ }^{3}$ The * denotes steady-state values. There is a second steady-state that, however, implies a negative value of $y$.

${ }^{4}$ A Hopf bifurcation means that the system might bifurcate to a stable limit cycle.
} 
If we raise the rate of time preference we see that for values of $\rho$ larger than about 0.075 we again get transitory oscillations. For $\rho$ larger than about 0.265 the system becomes unstable and the steady-state value for parasites turns negative.

As regards the comparative statics of a higher productivity we see that total production of the agricultural sector in the steady-state only rises by a small degree, about $0.1 \%$, and consumption of the agricultural product slightly declines whereas investment rises. The small increase in total production is due to fact that, in the steady-state, the number of parasites strongly increases, in our example by about $127 \%$, which dampens a larger increase of total food production.

Next, we raise the available land by setting $K=1.5$. The other parameters are as above, with $h=0.5$ and $\rho=0.03$ leading to the following steady-state,

$\left\{x^{*}, y^{*}, z^{*}, \lambda_{1}^{*}, \lambda_{2}^{*}, \lambda_{3}^{*}, c_{x}^{*}, c_{z}^{*}\right\}=\{5.507,0.014,0.705,0.233,-30.695,3.131,5.365,0.168\}$.

The eigenvalues are again complex conjugate with three having negative real parts showing that the dynamics are the same as in the case with $K=1$. This implies that the amount of cultivable land does not affect the short-run dynamics.

This shows that more land available (higher $K$ ) leads to a strong increase of the land used for non-agricultural purposes, $c_{z}$, which rises in our example by about $127 \%$. Further, we see that the steady-state value of land (used for food production) rises only slightly, steady-state food production and the steady-state number of parasites also slightly increase. Consumption of food slightly declines whereas investment in food production is increased. Investment is increased because with more land available it becomes more profitable to invest in the production of agricultural products.

Based on these numerical examples we can state the following results for our model economy: ${ }^{5}$

A lower value of the rate of time preference tends to stabilize the economy in the sense that transitory oscillations disappear for a sufficiently small value. The same holds for a higher productivity of the input factors in food production.

A higher productivity in food production raises steady-state production only to a small degree but leads to strong increase in the number of parasites. Steady-state consumption slightly declines while investment rises.

\footnotetext{
${ }^{5}$ For a higher elasticity of output with respect to land, $\gamma$, the results are the same from a qualitative point of view.
} 
An increase in the amount of totally available land strongly raises the use of land used for non-agricultural production in steady-state while agricultural production rises only slightly. Steady-state consumption of agricultural production slightly declines while investment rises.

Note that from the above equations we get the equilibrium solution for the relative price of agricultural products and land as the ratio of $\lambda_{1, t} / \lambda_{3, t}$, i.e. relative prices are given by the ratios of the corresponding co-state variables. If there are changes in preferences, such as the change of the discount rate, or changes in the production conditions, this will change the marginal utility of consumption of those two goods and this will via the costate variables change relative prices. This would hold in a frictionless environment. ${ }^{6}$ Yet, recent volatility and trends in commodity prices seem to suggest that the actual prices are not driven only by changes in the fundamental factors mentioned above. All of the above-discussed changes in the supply of land (negatively affected by the use by developers, for example, flooding or desert formation, use of land for bio-fuel, and positively by deforestation) will affect relative prices in the long run. They may also cause changes in the technology used in the production of agricultural commodities. However, we have yet to distinguish between theoretical prices, as studied above, and actual prices.

\section{Spot Prices and Future Prices}

The fact that actual prices are not equilibrium prices was already stated by Walras. He mentions that the equilibrium state of a market never materializes. Walras knew that the price signals, arising from supply and demand constellations in the market, cause agents to respond with offers and demands. However, this could not lead to actual trade since real resources would have to move at "false" (non-market clearing) prices. Thus, markets would be resource-wasting, volatile, and potentially unstable.

The excess demand theory of the 1950s and 1960s attempted to deal with this and introduced, into General Equilibrium, the concept of the excess demand function, for example

$$
\dot{p}_{i}=\gamma\left(D\left(p_{i}\right)-S\left(p_{i}\right)\right)
$$

Here, it is excess demand that moves prices; but it was demonstrated that in only two exceptional circumstances would the excess demand function be stable. These are (a) gross substitution and (b) the weak axiom of revealed preferences. Both cases create

\footnotetext{
${ }^{6}$ Note that we could use approximations to the above-suggested solution techniques (the Hamiltonian approach). These would give us price approximations in a finite-horizon model. Such methods are discussed in Grüne and Pannek (201 I).
} 
a downward-sloping demand function and will stabilize the excess demand functions. Yet, the excess demand function did not allow offers, or supply if production is included, to respond in a discrete manner to non-clearing market prices. In general, it is not established that if prices respond to excess demand, and if demand and supply respond to disequilibrium prices in a discrete manner, that this mechanism is stable. The most that can be hoped for is that prices - and quantities - may fluctuate in a cyclical manner. ${ }^{7}$

Such a cross-dual dynamic process between prices and quantities suggest that imbalances in demand, $D(p)$, and supply, $S(p)$, both depending on the price, $p$, will move prices at some adjustment speed which is represented in our above equation by $\gamma$. Demand falls as prices rises - a downward-sloping demand curve. Concerning changes in supply, imbalances in prices and costs (costs including a normal return on used capital assets) will move output. Since, in the latter case, there will be gains and losses in profits, producers may scale up production, when there are gains, or withdraw, when there are losses. Usually, this produces distinct oscillatory movements around some attracting points. ${ }^{8}$

On the other hand, since the 1930s, another process for market dynamics has become stylized, mainly by Keynesian economists. This is termed "dual dynamics." In this case, if prices are too high, as compared with what competition among firms may justify, prices may move down. Further, if demand is higher than supply, inventory will be sold (or built up, if there is excess supply) and new production capacity will be built (or reduced) to remove the excess demand. This dual process is not easily shown to be stable. ${ }^{9}$

Recent work on commodity prices has attempted to go beyond the above sketched classical mechanisms and suggested new price formations and quantity decisions as seen operating in future markets. An important paper is the one by Munier (2010). He also suggests that markets - in particular for commodities - will not converge to any equilibrium. He stresses that for primary products, the market mechanism will be exacerbated. Further, he suggests that there is a financialization of commodities that results in buying and selling which is mediated through futures markets. In this way, financial transactions have amplifying effects on the instability mechanisms of the market and produce high volatility. Munier describes this as the impact of informational externalities on actual spot prices. This is a good point; he states: "Each time a contract is concluded on the forward market, it informs and influences transactions on the spot market..."

\footnotetext{
${ }^{7}$ See Flaschel and Semmler (1987).

${ }^{8}$ For details, see Flaschel and Semmler (1987).

9 See Flaschel, Franke and Semmler (2007: ch. 2).
} 
(Munier, 2010:6) Thus, there is an "induced spot price" and many different prices will prevail on the Over-The-Counter (OTC) market, which will spill over to spot prices. Thus, equilibrium models of market models cannot give us a "reasonable approximation of such volatile and continuous markets with informational externalities."10

If one looks closely at the mechanism that Munier (2010) suggests, one sees that it includes elements of both of the above discussed mechanisms in it, but more of the second type. Yet there are shortcomings: inventories are increasing with excess supply, yet the impact of the build up of inventories is not modeled. On the other hand, in his model, prices are corrected when there is a discrepancy between the anticipated and the realized price. Heterogeneous traders (naïve and conservative investors) respond to the differences differently, and they - Munier here follows the agent-based model paradigm - leave a different impact on the prices, implemented by some timevarying weights. Thus, the supply is following the anticipated price (the classical cross-dual mechanism); yet, the price change is more represented by the dual process.

Viewing the agent-based price determination process proposed by Munier from the perspective described above, we can say that the process that Munier has sketched maybe incomplete, yet it represents an interesting mechanism of the spillover effects from future to spot prices. We can say, on the one hand, that market and price decisions are already very complex in Munier's model; yet, on the other, still too simple.

Specifically, some influences are missing which are highlighted by the cross-dual and dual dynamics:

- The price that Munier constructs as a result of the interaction of naïve and conservative investors may move upward for a while, independent of demand. Yet, the medium run demand may be affected by a rising prices - if prices get too high, demand will finally react (maybe through buyers' reaction or substitution). Thus, there should be some upper bound beyond which demand curves become downward-sloping again.

It is questionable if the producer's decision is impacted only by very short-run price fluctuations; medium-run prices are not used as guidelines for producer decisions. Producers need to extract some signals from the market for their production decisions. What price signals do the producers take? It should not be the noise in the signal, but rather some expected price in the medium run. In the Munier model, it is the anticipated price; but the anticipated price is just a function of some short run prices. Producers would not be well advised to take this as a signal as there might be too much

${ }^{10}$ For more discussion, see Semmler and Bernard (2010). 
short-run noise in it. Some price trend is important to them - see below. Moreover, inventory should also impact producers' output decisions, at least in the short run.

In Munier's model, one does not know future inventory, ${ }^{11}$ i.e., it can become very large or negative, and it has no impact on production and price decisions. Usually, inventories respond to prices, in particular to anticipated prices. Inventories cannot approach plus or minus infinity. Although Munier states that the change of inventory will "remain non-negative" in his simulations, the mechanism is not distinct for the reader.

In an agent-based approach, the market and price decisions are very complex; but in some sense they remain too simple and, often, simulation results generated using a simple underlying decision structure show up with significant price volatility.

On the other hand, our model, defined in Section 2, may only reveal some forces of long run price determination. As also discussed above, the land available for produce may increase through deforestation, but may also be reduced, due to the use of land for other purposes, e.g., development or bio-fuel. Moreover, flooding and droughts, resulting from heat waves, may reduce usable land. Natural predators, as portrayed in the equation, may increase or decrease over time, affecting the available renewables as defined above. Fertilizers and new production technology may give rise to higher output, but the rise of temperature and flooding may result in lower output of renewables. On the other hand, changes in preferences and population growth may affect the consumption of the two goods, $x$ and $z$, and thus the demand for them.

So, overall, a complex interaction of the spot and future markets for commodities is expected, as stylized in the work of Munier (2010), giving rise to short run complex pricing and quantity decisions and volatility. Yet, the model shown in Section 2 may suggest some underlying forces generating long run trends in output and the prices of renewables.

\section{The Volatility and Trend of Prices for Renewables}

Let us look closer at the empirical facts on trends and the volatility in the prices of primary commodities. The volatility of agricultural prices is clear from Figure 1. As the index for the agricultural raw materials and agricultural food price index show, they are extremely volatile. One might call these types of commodities "renewable" commodities. Renewable commodities have a long delay in production and market signals are

\footnotetext{
"See our discussion of future-flow securitizations in Section 5.
} 
converted slowly into supply responses. Although their supply is inelastic, they are reproducible and their prices may not have a trend. This seems to confirm Deaton's statement (1999) that renewable commodities have high volatility but little trends.

\section{Figure 1. Price trend and volatility of agricultural commodities}

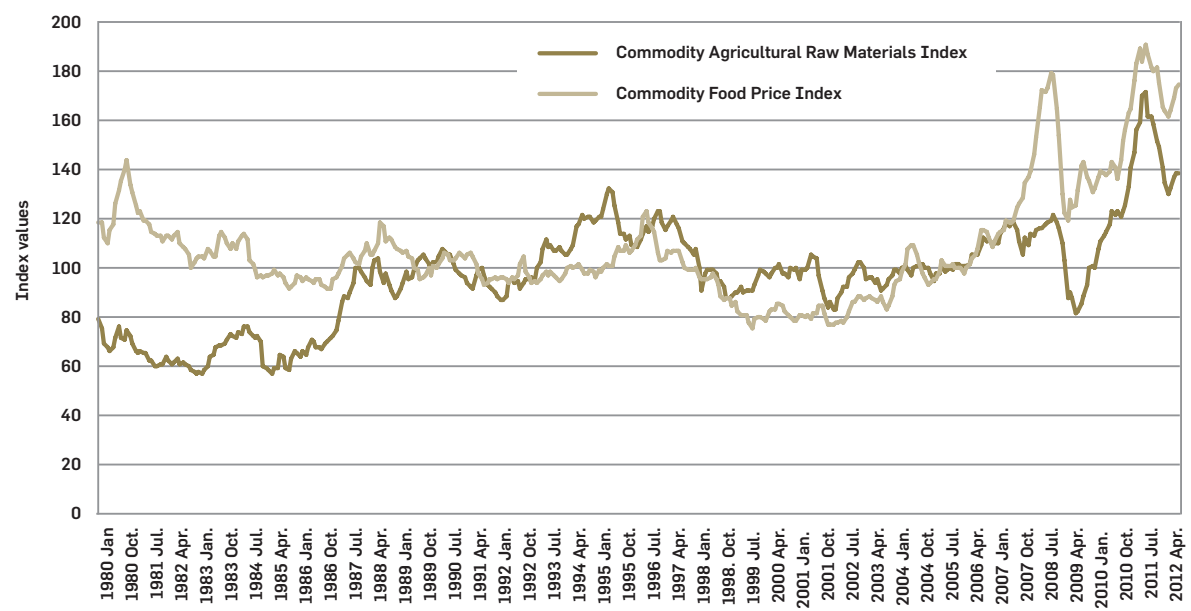

On the other hand, one seems to be able to observe that there are also price trends for the renewables.

\section{Figure 2. Volatility of non-reproducible commodities is higher}

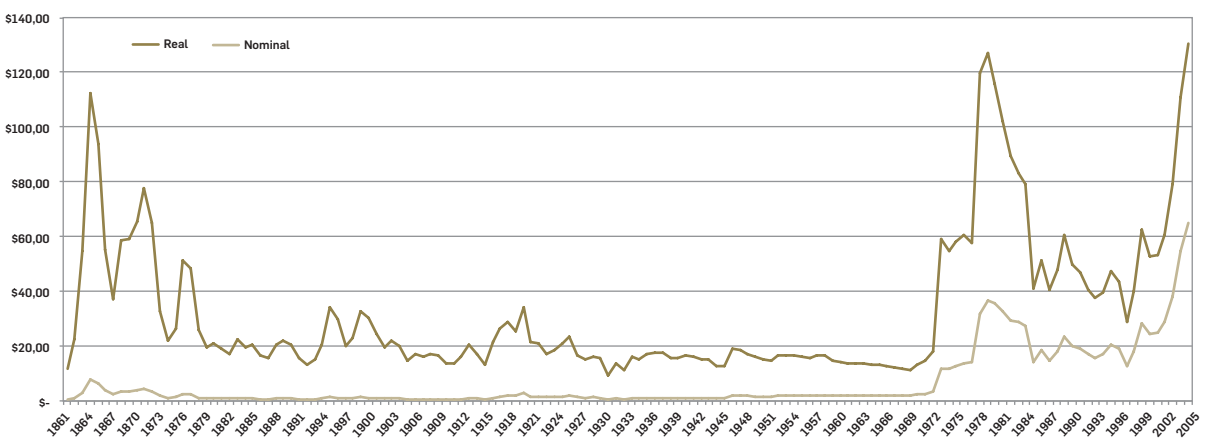

The price trend is different for non-renewable commodities ${ }^{12}$ which have both a high volatility but also a more visible price trend. This is shown in Figure 2, where spot oil prices since the end of the $19^{\text {th }}$ century is depicted for both nominal and real oil prices. As one can observe, there is a U-shaped trend in addition to high volatility. For an

\footnotetext{
${ }^{12}$ For an excellent econometric study of the price volatility in renewable and nonrenewable resources, see Enders and Holt (20I I).
} 
explanation of the $U$-shaped trend in non-renewable commodities, see Greiner and Semmler (2011). The volatility of renewable commodities and non-renewable for recent times is compared in Table 1.

Table 1. Historical Volatilities, $\mathbf{1 9 8 0 - 2 0 0 8}$

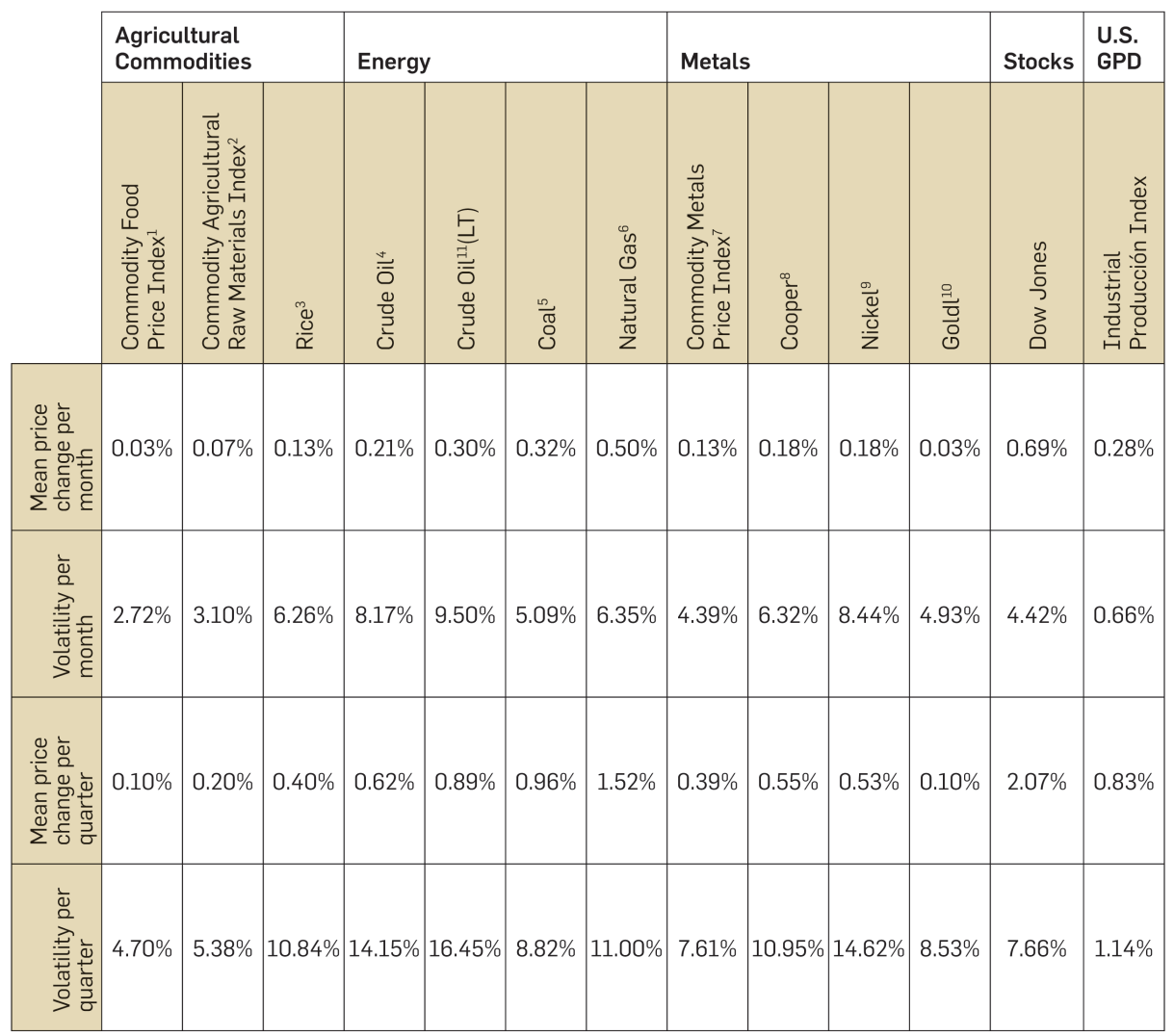

All samples from data, 1980-2008.

Source IMF. (Exception:The time series "Oil” are nominal annual oil prices from I860-2007.)

I) Includes Cereal, Vegetable Oils, Meat Seafood, Sugar, Bananas, and oranges Prices Indices.

2) Includes Timber, Cotton, Wool, Rubber, anf Hides Price Indices

3) Five percent broken milled white rice, US\$ per metric tonne.

4) Simple average of three spot prices; Dated Brent, West Texas Intermediate, and the Dubai Fateh.

5) Australian thermal coal, I2000-btu/pound, less than I\% sulfur, I 4\% ash, FOB Newcastle/Port Kembla. US\$ per metric tonne.

6) Russian Natural Gas border price in Germany, US\$ per thousands of cubic meters of gas.

7) Includes Copper, Aluminum, Iron Ore, Tin, Nickel, Zinc, Lead, and Uranium Price Indices.

8) Grade A cathode, LME spot price, CIF European ports, US\$ per metric tonne.

9) Melting grade, LME spot price, CIF European ports, US\$ per metric tonne.

10) Price in US Dollars US\$loz.

II) Nominal annual oil prices, long-term: 1860-2007.

As Table 1 shows, for the period of 1980 to 2007, the mean price change per quarter for agricultural, and thus for renewable resources, is lower than for non-renewable resources. Although the volatility of price changes are at least four to five times higher than for GDP growth it is only half of the quarterly volatility of non-renewable resources. Thus, overall, the volatility and the trend of agricultural products have to 
be put in perspective. It seems to be important to see that there is a weak price trend in renewable products, only visible, however, for some time periods. Yet, overall, the price trend is weaker than for non-renewables. The volatility is an important issue, and it seems to be in particular important for non-renewable commodities. Munier's considerations on the informational externalities arising from financial contracts seems to be even more important there. Financialization of renewables, as well as non-renewables are an increasingly important issue, as Munier states, but we will discuss this from another perspective.

\section{Securitization and Financialization of Commodities}

Now we will treat some basic concepts of the securitization of commodities.

\subsection{Basic Characteristics of Securitization}

Future-flow securitizations and diversified payment rights securitizations are two examples of non-uniform securitizations that need to be considered when studying commodities markets. Differences in countries, products, potential risks, constraints, perceived value, fiscal policies, market sizes, and trends in different marketplaces make it difficult to make these securitizations standard. Non-uniform securitizations were first known as "asset-backed securitizations" in the early 1990s. They became known as "non-uniform securitizations" as their popularity grew globally and their restrictions and parameters begin to vary. Future-flow Securitizations and Diversified Payment Rights (DPRs) are two of the best known.

Initially, future-flow securitizations became popular because they were an easy way for businesses in developing countries to obtain low-cost, long-term loans. Reputable public and private sector entities in these countries were able to raise funds in typically hard-to-reach capital markets and obtain higher credit ratings than their own governments. Thus, by establishing themselves in foreign markets, companies in developing countries were able to overcome domestic credit ceilings and access cheaper foreign financing. These actions also tend to lessen or prevent the panic that may occur if their respective country's domestic or foreign reserves became depleted. Even in a porous economic climate such as today, securitizations of future flow receivables in emerging markets appear to perform well (Mohapatra, 2008). This is because the securitization of credit cards, tourism, trade, DPRs and other assets that were formerly not securitized are enabling developing countries to maintain their access to international capital markets, even in times of economic crisis.

The standard features of securitizations include the process by which selected assets are pooled together to be repackaged and sold to investors as interest-bearing 
securities. This process originated in 1938s when U.S. government created Fannie Mae, and later, Freddie Mac, which pooled together home mortgages - the default risk to be resold to other investors; these large pools of home mortgages were sold as collective assets known as mortgage backed securities (MBS), shown in Figure 3 below. Later, in the 1980s, other assets began to be securitized and the securitization market grew dramatically. Many financial institutions used securitization to transfer the credit-risk of assets from their balance sheets to other financial institutions, such as hedge funds, insurance companies, and banks.

Securitized assets are relatively cheap to hold because rating agencies have set easier standards for them than for the larger, non-securitized assets that they were originally taken from. Securitization also lowers the concentration of risk by spreading it across multiple entities (Jobst 2008). A portfolio of securitizations is divided into several sections, known as tranches, for example, equity, mezzanine, and senior. Each tranche is sold individually due to their varying levels of risk.

"Equity" has the most risk, mezzanine has the median level of risk, and senior tranches have the least amount of risk. Investment return, (which includes interest and principal repayment), and losses are distributed among the tranches based on their risk levels. Risk is, thus, concentrated in the junior tranches. Thus, they also have the highest return to investors. Senior tranches have extremely low risk because of their low loss expectations. Investors often finance senior tranche purchases by borrowing from elsewhere.

Any asset that supports a stable cash flow can be placed into a reference portfolio and sold as securitized debt, which is why securitization has become so popular and has spread to smaller and emerging markets in recent years. In addition to mortgages, securities can be backed by individual lending agreements, home equity loans, consumer credit, small business loans, corporate loans, sovereign loans, project nance, lease receivables, and trade receivables. These securities are known as "asset backed securitizations" or "ABS".

Additionally, a variant is a Collateralized Debt Obligation (CDO) which uses the same process as ABS, but includes a larger and more diverse set of assets. Securitization originated as a way for financial institutions and corporations to find new sources of funding. It allowed banks to move assets off of their balance sheets or borrow against their assets to refinance their organization at a fair market rate. It also reduced their borrowing costs and in the case of banks, it lowered their minimum regulatory capital requirements (Jobst, 2008). A major reason for the reduction in costs is because the assets are detached from the originator's balance sheet and credit rating, thus allowing the issuers of the assets to finance the purchase of the assets more cheaply than if they were not securitized. 
Securitization does not inflate a company's liabilities as conventional debt does. Instead, securitization produces funds for future investment without balance sheet growth. Through the securitization process, investors are able to quickly adjust their portfolios in response to changes in transactions costs, preferences, and market volatility. Occasionally, securities are not sold directly from the originator to the issuer, which is called "true sale securitization". Instead, the originator sells only the credit risk associated with the asset, without the transfer of its legal title; this is called "synthetic securitization". Synthetic securitization enables the issuers to exploit price differences between the acquired, (and often illiquid), assets and the price investors are willing to pay for them if they are diversified in a larger pool of assets (Jobst, 2008).

\section{Figure 3. Mechanics of Securitization (MBS)}

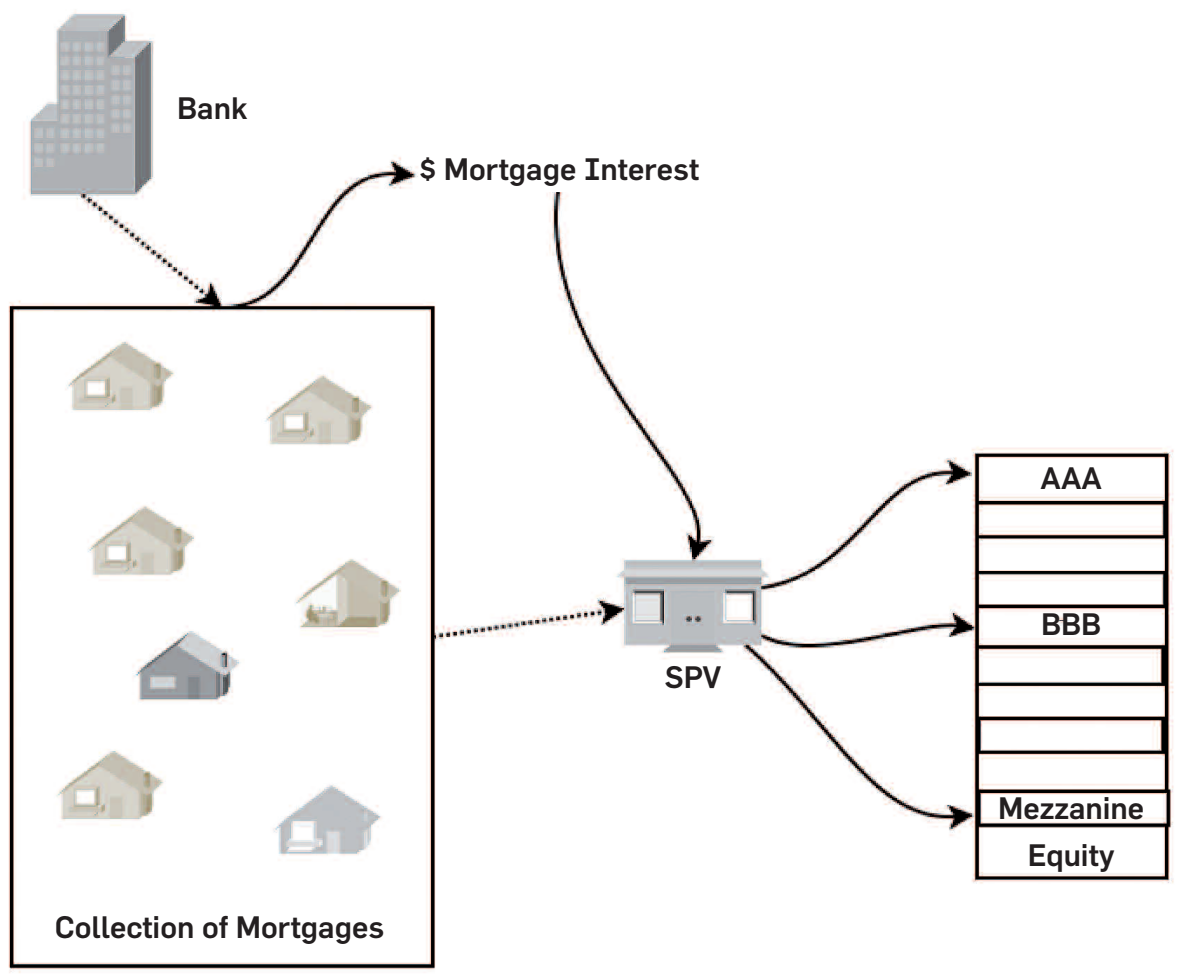

\subsection{Mechanics of Future-Flow Securitization}

Future-flow securitizations can be thought of as a sequence of steps (Bernard, Semmler and Schron, 2011). First, the established country receiving the exported foreign funds to be used as future-flow receivables has the foreign funds converted to their sovereign currency in order to raise more funds in the same or other markets. Second, the trustworthy country receiving the future-flow receivables establishes an "SPV", (Special Purpose Vehicle; also known as an "SPE" - "Special Purpose Entity" in some regions or Structured Investment Vehicle, "SIV"), in a tax neutral location outside the foreign 
country receiving their loan(s). Third, the lending country sells its current and future export receivables to the SPV for a lump sum payment; or the lending country agrees to give the receivables to the SPV as security for a different loan from the SPV. A description of cash flows for a typical future-flows securitization is shown in Figure 4, below.

Occasionally, the original lending country who also established the SPV inherits liability by agreeing to repurchase the receivables from the SPV under unique predetermined circumstances. Next, the SPV funds the original loan/purchase price by issuing securities backed by its right to receive the existing and future-flow receivables. During a revolving period, the developing country acquiring the export receivables pays the SPV by putting their payment in the SPV's personal, independent, offshore bank accounts. The SPV uses the received payment to pay their own scheduled interest and principal payments on the securities exchanged and any other transaction costs; the remaining cash from the original payment to the SPV is given back to the original payee country. Once the revolving period expires or is completed, all of the cash from the original payment to the SPV for the future-flow receivables is used to pay the interest and principal on the securities until they have been paid in full.

The most desirable attribute of future flow securitizations is that they allow countries with external foreign currency debt ratings less than investment grade to obtain outside funding from international capital markets from a more credible source than otherwise possible. Thus, the borrowing country may bypass the "sovereign ceiling" because they can issue securities that are rated more highly than their native country's external foreign currency debt rating.

\section{Figure 4. Typical future-flows securitization}

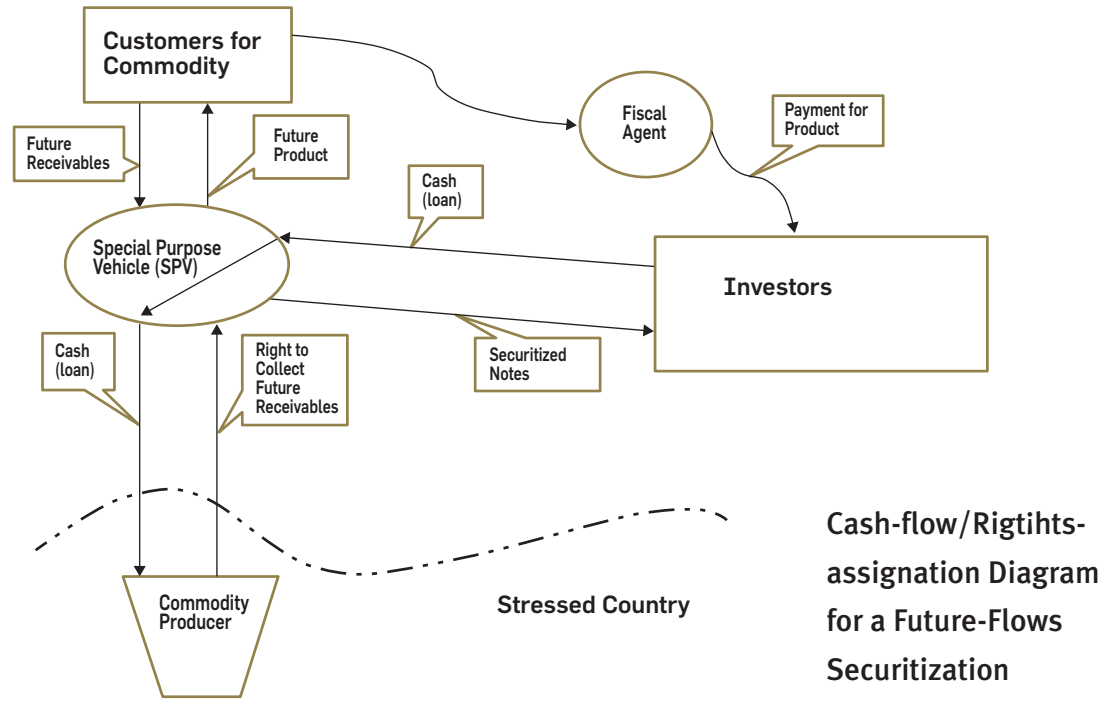




\subsection{The Economics of Recession and Commodities}

As of late, securitization has become a larger player in commodities markets. The current global economic downturn combined with the recent credit crisis have increased the demand for both future flow receivables and DPRs. The ratings of sovereign debt has decreased causing the numbers of potential borrowers to grow even though their respective abilities to produce goods or the potential demand for these goods may have not changed.

If a joint agreement is reached between the business producing the good, the customers for its good, and an off-shore/outside partner group which agrees to lend money to the producing business in exchange for the rights to the proceeds of the sale of the good to be sold to the producing country's customers, the off-shore/outside partner group may agree to lend guaranteed ("collateralized") funds to the producing country in exchange for the future cash ow produced by the sale of its goods to its customers. Although there is some risk involved, the risk decreases because the guaranteed cash flow comes from the outside creditworthy lending country, which in turn results in a lower price for credit. This process has similarities with the sub-prime loan crisis that occurred within the last few years. Lenders would finance loans collateralized by homes and the future earnings of the borrower would pay for the interest on these loans. In the future flow securitization process, the future sale of commodities will pay for the interest on the loans.

In both scenarios, the increasing price of the collateral reassures the investor of receiving his/her future payments from the borrower(s). In the recent, and still current economic downturn, "CMOs" ("Collateralized Mortgage Obligations") are standardized and traded like stocks. In equity markets, a tremendous amount of trade comes from institutions and active traders balancing their market positions; connecting the two separate transactions is the fact that much of the trading in CMOs during the recent economic downturn has more to do with large and small market players adjusting their portfolios and less to do with confidence in the real estate market. Moreover, active market players have helped spur the growth of commodities markets from an estimated $\$ 643$ million in 1994, to $\$ 5.2$ billion in 2004 , to an estimated $\$ 80$ billion at the beginning of 2010 (Semmler \& Bernard 2009).

Although leveraged financing schemes are inherently risky, and thus the demand for higher returns by borrowers, CMOs are especially dependent upon the default rate. Much along the same lines, overestimates by financial intermediaries and regulatory bodies about the incomes of home-owners weakened the CMO market and played a catalyzing role in current recession, there is a similar risk relating to commodities: Due to the necessity of looser financial restrictions when it comes to secondary markets, the value of commodities are skyrocketing, perhaps with negative future 
ramifications. Even though contracts in commodity markets are normally private and require additional informational services to assess their quality and risk, it is plausible to compare the role CMOs played in the current financial crisis to the potential role commodities could play in prolonging this current economic crisis, or creating a new credit crunch in the future.

First o, much of the demand for commodities has been derived from the 2007 downturn, because commodity producers were searching for lenders due to the increased borrowing costs imposed by declining sovereign debt ratings. Additionally, lenders wanted to lock in yields above what could be obtained in more conventional money markets because they became more risk-averse now than possibly ever before. Second, the demand for most commodities can only be expected to increase. If the aforementioned theories hold true, which is seeming more and more likely as time goes by, the movement in commodities prices may actually be caused by, (NOT correlated to), a growing market in securitized products for their future cash flows. Third, one has to note that volatility in commodity prices, both renewables and nonrenewables, are actually much higher than seen in real estate prices. So, the risk for insolvency and the potential for disruption will be higher in the former than the latter.

\subsection{Agricultural Commodities and their Financialization}

Agricultural commodities are important in both developed and developing countries. As agricultural commodities can be key economic exports, volatile prices can produce a great deal of risk. For example, even if production is decreased when demand initially decreases, the agricultural sector will suer job losses. Radical movement in commodities prices makes their pricing mechanism difficult to decipher. Thus, creating standardized securities across international markets is complex. In fact, commodities are much more volatile than corporate bonds or real estate investments. ${ }^{13}$

This leads many to believe that these structured financial products, which are very sensitive to prices and are dependent on default risk, may play a role. These assets reflect an increase in systematic risk in the same way that real estate was paired with unrealistic default rates in some of the packaged securities. This same situation is likely to occur in the commodities market because of its greater volatility. To make matters worse, commodities' prices are sensitive to exogenous factors such as political, economic, meteorological, and geographical factors, as well as other unpredictable factors. Moreover, because commodities are used in a variety of ways, simulation based on empirical evidence is more appropriate than creating a "causal" or closed-form pricing model.

\footnotetext{
${ }^{13}$ More discussion along these lines may be found in Bernard, Semmler, \& Schron (20II).
} 
Volatility of the excess demand for agricultural commodities, both current and future, is always an issue. Corn is an example, both as food for livestock and as ethanol. Due to government programs encouraging domestic producers of ethanol, corn has been experiencing high demand for some time. But the increase in demand for corn can lead to other problems. For example, as corn prices rise, farmers have less corn to feed their livestock with, and may be forced to sell some off. This, however, takes time as farmers will search for the best buyers and negotiate for the highest prices. Thus, the price of meat prices remain low because livestock buyers know that farmers need to get rid of livestock in order to slow their losses. (Schmidt, 2010). In turn, as the supply of livestock decreases, the international price of meat may rise, causing underdeveloped nations to consume less protein. Thus, higher grain prices have catalyzed higher prices for agricultural assets in equities markets.

Most investors do not want to get involved with future flow receivables and invest in proxies instead, e.g., fertilizer companies serve this role with respect to grain equities. The investment in proxies may artificially inflate their prices in the short run. When the harvests are completed early or on time, and the harvest's size and condition are close to predicted market values, it may cap agricultural equities prices for the short term. Moreover, currency fluctuations may make U.S. agricultural goods cheaper, thus raising the purchasing expectations of domestic grain harvesters and traders.

Developing nations frequently invest in agricultural infrastructure and innovation because of their available untapped natural resources or potential contributions to global markets if their societies are improved. A diverse group of agricultural commodities are also traded in many exchanges around the world. Trading agricultural commodities strengthens their business and individual market by allowing farmers to lock in constant prices for the future. Without the trade of agricultural commodities, farmers would be more at risk for losing the value of their crops to unpredictable negative events, such as natural disasters. ${ }^{14}$ These all may be mechanisms for hedging and buffering risk. Yet, as we have discussed above, the financialization of commodities can create new sources of risk.

\section{Conclusions}

We have built a model of the production of renewable commodities, such as agricultural products. We do not use a production function for renewable commodities, but rather study the production of those commodities in the context of a dynamic decision approach.

\footnotetext{
${ }^{14}$ Practical information on agricultural commodities can be found at http://www.wisegeek.com/whatare-agricultural-commodities.htm
} 
Agricultural commodities, considered here as renewable products, are critical to many developing countries. Not only are their prices rising, along with price volatility on both spot and futures markets, but also an increasing financialization of these products is making itself felt. Financialization can help to buffer risk, but can be a new source of risk in and of itself. All this might become a threat to many segments of the populations of low income countries. Our model helps one to understand how economic and financial effects interact to produce, for example, food shortages, volatility in food supplies, and the consequent volatility in food prices.

We have also explored the consequences of securitization and the financialization of commodities through financial markets. If it were possible to come up with a way to make securitizations standard, so they could be traded, bought, and sold in marketplaces across the globe, e.g., through commodity buffer stocks, ${ }^{15}$ the current crisis could be controlled/corrected through mechanisms, which could give rise to a more steady global development. On the other hand the number and type of assets that are able to be securitized have increased enormously in recent years, and will continue to do, especially if internationally accepted standards are created for securitizations. Yet, will the borrowing agents in a country receiving the loans from the established lending country actually use the funds for the same purposes that they promised to? (Moral Hazard quandary); does the borrowing country know enough about the established and more developed country lending them money to know if they are getting a fair deal or not? (Adverse Selection problem). As soon as a solution to making non-standard securitizations standard through regulatory agents (as derivatives are planned to be treated under the Frank-Dodd Act), it will be easier to create variations of this solution, generating a smoother commodity market.

\section{Acknowledgements}

The authors would like to thank Sanjay Reddy for his comments and extremely helpful suggestions.

${ }^{15}$ This idea of creating commodity buer stocks goes back to Benjamin Graham and to John Maynard Keynes in the 1930s, later revived by Nicholas Kaldor in the 1960s. 


\section{References}

Asian Development Bank ("ADB") (2007). Report and Recommendations of the President to the Board of Directors. Project Number 40941: July.

- Bernard, L., Semmler, W. and Schron, J. (2011). Non-Standard Securitizations: Their Economic and Financial Applications Potential, Journal of Technology and Investment, 2(1), pp. 1-7.

Culp, C. and Paul, J. (2009). Structured Financing Techniques in Oil \& Gas Project Finance: Future Flow Securitizations, Prepaids, Volumetric Production Payments, and Project Finance Collateralized Debt Obligations. Social Science Research Network. August <le://Users/JSMar16/Desktop/IS \%20New\%20Development\%20Article\%20\%233.webarchive>

Deaton, A. (1999). Commodity Prices and Growth in Africa, Journal of Economic Perspectives, 13(3), pp. 23-40.

Enders, W. and Holt, M.T. (2011). Breaks, bubbles, booms, and busts: the evolution of primary commodity price fundamentals. Unpublished.

Flaschel, P., Franke, R. and Semmler, W. (1997). Dynamic Macroeconomics: Growth, Instability and Fluctuations in Monetary Economies, MIT Press, Cambridge, MA.

Flaschel, P. and Semmler, W. (1987). Classical and Neoclassical Competitive Adjustment Processes, The Manchester School of Economic \& Social Studies, 55(1), March, pp. 13-37.

- Greiner, A., Semmler, W. and Mette, T. (2011). An Economic Model of Oil Exploration and Extraction, Computational Economics (11 June), pp. 1-13.

n Güne, L. and Pannek, J. (2011). Nonlinear Model Predictive Control, Springer-Verlag, London, UK.

- Jobst, A. (2008). Back to Basics, Finance and Development, 45(3), pp. 48-49.

- Mohapatra, S. (2008). How Remittance Securitizations Can Help Developing Countries During a Credit Crisis, People Move, 27 August 2008, http://blogs.worldbank.org/peoplemove

- Munier, B. (2010). Boundedly rational exuberance on commodity markets, Risk and Decision Analysis, 2(1), pp. 33-50.

- Schmidt, N. (2010). Food Prices Spiraling Higher, Grains Feed Meat Prices, The Market Oracle 21 October, http://www.marketoracle.co.uk/Article23658.html

- Semmler, W. and Bernard, L. (2010). Boundedly rational exuberance in commodity markets - Some comments on Bertrand Munier, Risk and Decision Analysis, 1, pp. 51-58.

- Semmler, W. and Bernard, L. (2011). Boom-Bust Cycles: Leveraging, Complex Securities, and Asset Prices, Journal of Economic Behavior and Organization, doi:10.1016/j.jebo.2011.07.002 
